Jurnal ELTIKOM, Vol. 1 No.1, Juni 2017, Hal 31-38

ISSN 2598-3245 (Print), ISSN 2598-3288 (Online)

Tersedia Online di http://eltikom.poliban.ac.id

\title{
PERENCANAAN STRATEGIS SISTEM INFORMASI
}

\author{
Ronny Faslah ${ }^{1)}$ dan Abdul Haris ${ }^{2)}$ \\ ${ }^{1,2)}$ Teknik Informatika Universitas AMIKOM Yogyakarta \\ e-mail: roffa@poliban.ac.id ${ }^{1)}$, abdulharis@wicida.ac.id ${ }^{2)}$
}

\begin{abstract}
As one of the higher education institutions, STMIK WICIDA continues to improve the competitiveness of universities in the midst of similar college competition in East Kalimantan. Competitive advantage is not only obtained through strong human resources, financial, and management but also can be obtained through the use of information and communication technology. To gain a competitive advantage through the use of information and communication technology, WICIDA STMIK must have a strategic design of information systems, so that in line with the vision, mission and objectives. This research uses IS / IT Strategic model initiated by Ward and Pepperd. The analysis was performed using PEST tools for external environment analysis, Value Chain for internal business environment analysis and mcFarlan Strategic Grid for internal IS / IT environment analysis. The final result of this research is recommendation of strategic planning of information system at STMIK WICIDA.
\end{abstract}

Keywords: Strategic planning of information systems, PEST, value chain analysis, mcFarlan Strategic Grid.

\begin{abstract}
ABSTRAK
Sebagai salah satu lembaga pendidikan tinggi, STMIK WICIDA terus berupaya untuk meningkatkan daya saing perguruan tinggi di tengah maraknya persaingan perguruan tinggi sejenis di Kalimantan Timur. Keunggulan kompetitif tidak hanya didapatkan melalui sumber daya manusia yang tangguh, finansial, dan manajemen tetapi juga bisa didapatkan melalui pemanfaatan teknologi informasi dan komunikasi. Untuk mendapatkan keunggulan kompetitif melalui pemanfaatan teknologi informasi dan komunikasi, STMIK WICIDA harus mempunyai perancangan strategis sistem informasi, sehingga sejalan dengan visi, misi dan tujuannya. Penelitian ini menggunakan model IS/IT Strategic yang digagas oleh Ward dan Pepperd. Analisis dilakukan menggunakan tools PEST untuk analisis lingkungan eksternal, Value Chain untuk analisis lingkungan bisnis internal dan mcFarlan Strategic Grid untuk analisis lingkungan IS/IT internal. Hasil akhir dari penelitian ini adalah rekomendasi perencanaan strategis sistem informasi pada STMIK WICIDA.
\end{abstract}

Kata Kunci: perancangan strategis sistem informasi, PEST, value chain anaylisis, mcFarlan Strategic Grid.

\section{PENDAHULUAN}

$\mathrm{S}$ ejak didirikan pada tahun 1991, Sekolah Tinggi Manajemen Informatika dan Komputer Widya Cipta Dharma atau STMIK WICIDA telah berpartisipasi dalam penyiapan dan pengadaan sumber daya manusia (SDM) yang berkualitas dengan dasar pengetahuan manajemen dan ilmu komputer. Saat ini STMIK WICIDA telah memiliki tiga program studi yaitu Program Studi S1 Teknik Informatika, Program Studi S1 Sistem Informasi dan Program Studi D3 Manajemen Informatika. Berdasarkan data PDPT pada tahun 2017, STMIK WICIDA mempunyai 1.976 mahasiswa aktif dan didukung 33 dosen tetap. Dilihat dari jumlah mahasiswa aktif tersebut, STMIK WICIDA merupakan pemimpin pasar di segmen sekolah tinggi berbasis komputer di Kalimantan Timur.

Sebagai salah satu lembaga pendidikan tinggi, STMIK WICIDA terus berupaya untuk meningkatkan daya saing perguruan tinggi di tengah maraknya persaingan perguruan tinggi sejenis di Kalimantan Timur. Keunggulan kompetitif tidak hanya didapatkan melalui sumber daya manusia yang tangguh, finansial, dan manajemen tetapi juga bisa didapatkan melalui pemanfaatan teknologi informasi dan komunikasi. Untuk mendapatkan keunggulan kompetitif melalui pemanfaatan teknologi informasi dan komunikasi, STMIK WICIDA harus mempunyai perancangan strategis sistem informasi, sehingga sejalan dengan visi STMIK WICIDA yaitu "Menjadi Perguruan Tinggi Informatika dan Komputer terkemuka di kawasan Timur Indonesia".

Permasalahan utama yang dihadapi STMIK WICIDA dalam pengembangan sistem informasi adalah belum adanya rencana pengembangan sistem informasi yang terpadu sehingga pengembangan sistem 
informasi hanya berdasarkan kebutuhan yang terjadi saat ini tanpa mempertimbangkan pengembangan lebih lanjut. Sistem informasi yang sudah dikembangkan saat ini meliputi Website STMIK WICIDA, Sistem Informasi Akademik (SIAK), Sistem Informasi Penggajian Karyawan, Sistem Informasi Penerimaan Mahasiswa Baru dan Sistem Informasi Pelayanan Pembayaran Mahasiswa. Masalah lain adalah belum optimalnya pemanfaatan TI dalam pelayanan pendidikan, hal ini bisa dilihat dari terbatasnya bandwidth yang tersedia serta belum adanya pengelola sistem informasi sebagai penanggung jawab pengembangan sistem informasi dalam struktur organisasi STMIK WICIDA.

Permasalahan di atas timbul karena saat ini STMIK WICIDA belum mempunyai perencanaan strategis sistem informasi yang jelas. Untuk itu diperlukan perencanaan strategis SI/TI yang selaras dengan strategi bisnis STMIK WICIDA. Hasil akhir dari penelitian ini adalah rekomendasi perencanaan strategis sistem informasi pada STMIK WICIDA.

Penelitian Hariadi, dkk. pada STMIK Cahaya Surya Kediri menyebutkan bahwa perencanaan strategis sistem informasi dapat dibuat menggunakan metodologi Ward dan Peppard dengan alat bantu Value Chain Analysis, Five Forces Model dan mcFarlan Strategic Grid [1].

Penelitian Susena, dkk. pada perencanaan strategis sistem informasi smart campus di Politeknik Indonusa menyebutkan bahwa roadmap perencanaan strategis sistem informasi dapat dibuat menggunakan analisis Ward dan Peppard, analisis SWOT dan analisis PIECES [2].

Penelitian Suryadi pada perencanaan strategis sistem informasi dan teknologi informasi (SI/TI) yang mengambil studi kasus pada Universitas Budi Luhur menyebutkan bahwa kerangka kerja perancangan rencana strategis dapat diimplementasikan menggunakan metodologi yang dikemukakan John Ward dan Joe Peppard dengan alat bantu metode analisis PEST, analisis Five Forces Porter, analisis SWOT dan analisis Critical Success Factor (CSF) [3].

\section{LANDASAN TEORI}

\section{A. Perencanaan}

Perencanaan adalah suatu proses yang melibatkan penentuan sasaran dan tujuan organisasi, menyusun strategi menyeluruh untuk mencapai sasaran yang ditetapkan dan mengembangkan hierarki rencana secara menyeluruh untuk mengintegrasikan dan mengkoordinasikan kegiatan [4].

\section{B. Strategi}

Strategi dapat didefinisikan sebagai satu rangkaian tindakan-tindakan terpadu yang menjadi alat untuk meningkatkan keberhasilan dan kekuatan jangka panjang sebuah perusahaan dalam mencapai keunggulan bersaing [5].

C. Sistem Informasi

Sistem informasi adalah kombinasi sumber daya yang terorganisir dari manusia, perangkat keras, piranti lunak, jaringan komputer dan data yang mengumpulkan, mengubah dan mendistribusikan informasi pada suatu organisasi [6].

D. Strategi Sistem Informasi

Strategi SI adalah strategi yang mendefinisikan kebutuhan organisasi atau perusahaan terhadap informasi dan sistem yang mendukung keseluruhan strategi bisnis yang dimiliki organisasi tersebut [5]. Gambar 1 menunjukkan kerangka formulasi strategi dan perencanaan SI mengacu kepada model IS/IT Strategic. 


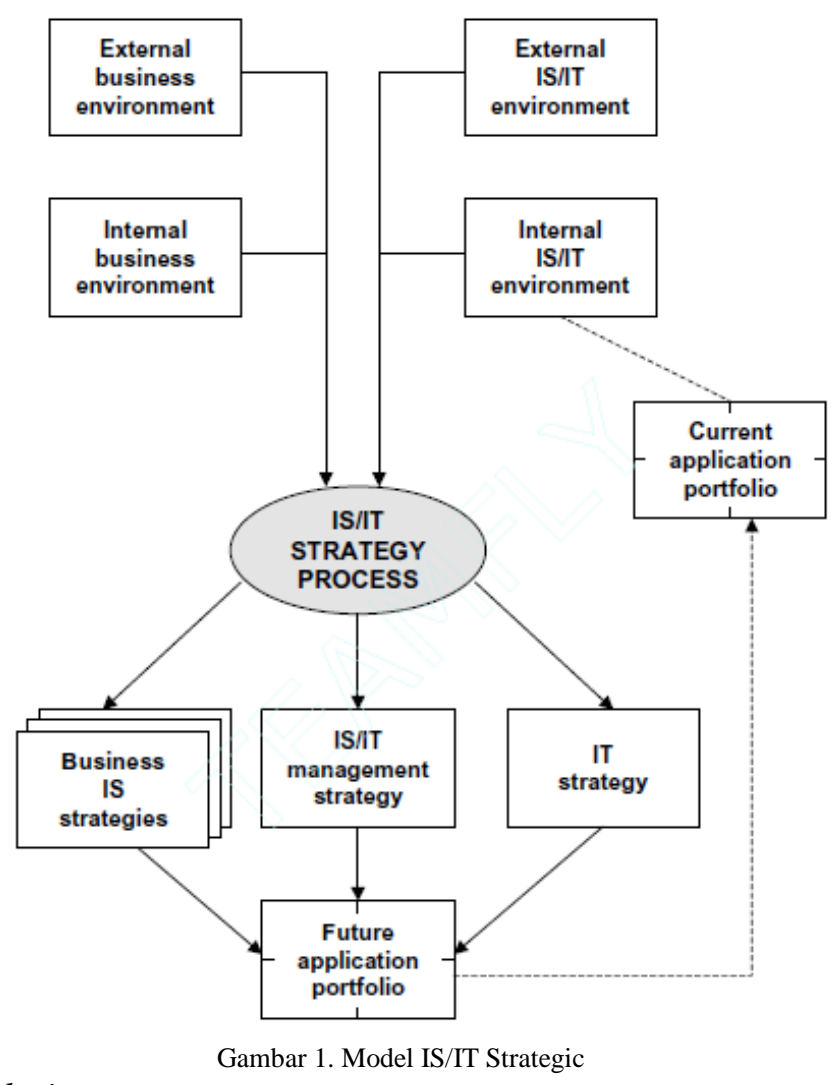

E. Value Chain Analysis

Value Chain Analyisis merupakan alat untuk memahami rantai nilai yang membentuk suatu produk. Rantai nilai ini berasal dari aktivitas yang dilakukan, mulai dari bahan baku sampai ke tangan konsumen, termasuk juga pelayanan purna jual.

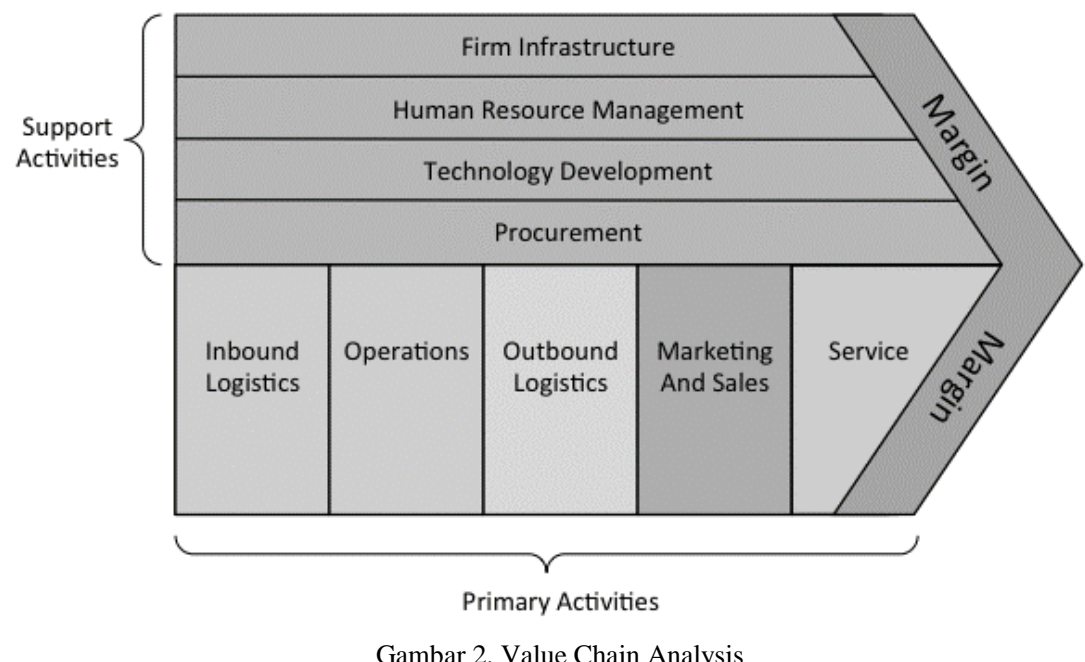

\section{F. mcFarlan Strategic Grid}

McFarlan Strategic Grid adalah model portofolio yang mempertimbangkan kontribusi IS/IT terhadap bisnis saat ini dan di masa mendatang berdasarkan dampaknya terhadap perusahaan [5]. Suatu aplikasi dapat didefinisikan sebagai strategic, high potential, key operational dan support tergantung dari kontribusinya terhadap kesuksesan bisnis. 


\begin{tabular}{|l|l|}
\hline \multicolumn{1}{|c|}{ STRATEGIC } & HIGH POTENTIAL \\
\hline - Applications that & - Applications that \\
are critical to & may be important \\
sustaining future & in achieving future \\
business strategy & success \\
\hline & - Applications that \\
- Applications on which & are valuable but \\
the organization & not critical to \\
currently depends & success \\
for success & \\
\hline KEY OPERATIONAL & SUPPORT \\
\hline
\end{tabular}

Gambar 3. mcFarlan Strategic Grid

\section{METODE}

Dengan mengacu pada model IS/IT Strategic yang digagas oleh Ward dan Pepperd, untuk membuat perencanaan strategis sistem informasi pada STMIK WICIDA akan melalui beberapa tahapan antara lain :

1. Analisis lingkungan bisnis eksternal menggunakan analisis PEST (Political, Economic, Social dan Technological).

2. Analisis lingkungan IS/IT eksternal dilakukan melalui penelaahan literatur.

3. Analisis lingkungan IS/IT internal dilakukan dengan menggunakan pendekatan mcFarlan Strategic Grid untuk memetakan portofolio aplikasi sistem informasi yang sedang berjalan.

4. Analisis lingkungan bisnis internal dilakukan menggunakan pendekatan Value Chain Analysis,

5. Penyusunan perencanaan strategis sistem informasi.

6. Rencana implementasi perencanaan strategis sistem informasi yang selaras dengan rencana strategis STMIK WICIDA.

\section{PEMBAHASAN}

A. Analisis Lingkungan Bisnis Eksternal

Untuk mendapatkan gambaran lingkungan eksternal bisnis, pengaruh serta kebutuhan SI/TI yang terkait dilakukan analisis PEST. Hasil analisis PEST dapat dilihat pada Tabel 1.

TABEL 1

HASIL ANALISIS PEST

\begin{tabular}{|c|c|}
\hline Politik & Kebutuhan IS/IT \\
\hline $\begin{array}{l}\text { - Undang Undang RI No. } 12 \text { tahun } 2012 \text { tentang Pendidikan } \\
\text { Tinggi. } \\
\text { - Peraturan Pemerintah No. } 4 \text { tahun } 2014 \text { tentang } \\
\text { penyelenggaraan pendidikan tinggi dan pengelolaan perguruan } \\
\text { tinggi. } \\
\text { - Permendikbud No. } 109 \text { Tahun } 2013 \text { tentang Penyelenggaraan } \\
\text { Pendidikan Jarak Jauh di Pendidikan Tinggi } \\
\text { - Permendikbud No. } 50 \text { Tahun } 2014 \text { tentang Satuan Penjaminan } \\
\text { Mutu Internal (SPMI) }\end{array}$ & $\begin{array}{l}\text { - Sistem Informasi Akademik yang terhubung dengan Pangkalan } \\
\text { Data Perguruan Tinggi (Feeder Dikti). } \\
\text { - Learning Management System untuk Pendidikan Jarak Jauh. } \\
\text { - Sistem Informasi Penjaminan Mutu Internal yang mampu } \\
\text { menyajikan informasi yang dapat digunakan untuk kebutuhan } \\
\text { akreditasi. }\end{array}$ \\
\hline Ekonomi & Kebutuhan IS/IT \\
\hline $\begin{array}{l}\text { - Dalam sektor pertambangan, Kalimantan Timur merupakan } \\
\text { penyumbang utama batu bara nasional. } \\
\text { - Pertumbuhan lahan perkebunan sawit yang terus meningkat. } \\
\text { - Permintaan tenaga kerja terampil pada sektor pertambangan } \\
\text { dan perkebunan. }\end{array}$ & $\begin{array}{l}\text { - Sistem informasi yang dapat menampilkan informasi profil } \\
\text { STMIK WICIDA sebagai pencetak tenaga kerja terampil } \\
\text { - Sistem informasi yang menyajikan informasi tentang lapangan } \\
\text { pekerjaan yang tersedia (Job Placement Center). }\end{array}$ \\
\hline Sosial & Kebutuhan IS/IT \\
\hline $\begin{array}{l}\text { - Corporate Social Responcibility (CSR) perusahaan- } \\
\text { perusahaan besar di Kalimantan Timur untuk pengembangan } \\
\text { masyarakat di sekitar lokasi usaha perusahaan. }\end{array}$ & $\begin{array}{l}\text { - Sistem informasi yang menghubungkan tiga pihak yaitu kampus, } \\
\text { masyarakat dan perusahaan dalam pemanfaatan dana CSR untuk } \\
\text { beasiswa calon mahasiswa. }\end{array}$ \\
\hline Teknologi & Kebutuhan IS/IT \\
\hline $\begin{array}{l}\text { - Perkembangan teknologi informasi dan komunikasi seperti } \\
\text { aplikasi web, aplikasi mobile dan cloud computing. }\end{array}$ & $\begin{array}{l}\text { - Sistem informasi yang dikembangkan harus mendukung } \\
\text { berbagai platform. }\end{array}$ \\
\hline
\end{tabular}


B. Analisis Lingkungan IS/IT Eksternal

Perkembangan teknologi informasi dan komunikasi yang begitu pesat dibarengi dengan peningkatan kebutuhan STMIK WICIDA terhadap teknologi informasi dan komunikasi dalam menjalankan proses bisnisnya. Beberapa perkembangan TIK yang dapat dimanfaatkan oleh STMIK WICIDA dapat dilihat pada Tabel 2.

TABEL 2

PERKEMBANGAN TIK

\begin{tabular}{ll}
\hline \hline Perkembangan TIK & Manfaat \\
\hline Aplikasi web & $\begin{array}{l}\text { Mempermudah pengolahan data dan } \\
\text { penyampaian materi pembelajaran yang interaktif } \\
\text { dengan memanfaatkan aplikasi web. }\end{array}$ \\
\hline Aplikasi Mobile & $\begin{array}{l}\text { Dapat dimanfaatkan untuk mengembangkan } \\
\text { aplikasi yang bisa dijalan pada platform mobile. }\end{array}$ \\
\hline Cloud Computing & Teknologi ini juga memungkinkan STMIK \\
& WICIDA melakukan efisiensi dengan \\
& memusatkan penyimpanan, memori, pemrosesan, \\
& dan bandwith tanpa mengeluarkan investasi awal \\
& yang besar. \\
\hline Open Source Learning Management System & $\begin{array}{l}\text { Memungkinkan mahasiswa STMIK WICIDA } \\
\text { untuk dapat mengakses konten pendidikan pada } \\
\text { portal-portal } \text { open source sebagai bahan belajar. }\end{array}$ \\
\hline \hline
\end{tabular}

C. Analisis Lingkungan IS/IT Internal

Analisis ini bertujuan untuk mengidentifikasi portofolio aplikasi sistem informasi yang sudah berjalan di STMIK WICIDA. Analisis ini dilakukan menggunakan pendekatan mcFarlan Strategic Grid yang memetakan aplikasi dalam 4 kuadran aplikasi yaitu strategic, high potential, key operasional dan support. Hasil analisis ini bisa dilihat pada Tabel 3.

TABEL 3

PORTOFOLIO APLIKASI SAAT INI

\begin{tabular}{ll}
\hline \hline Strategic & High Potential \\
\hline - Sistem Informasi Akademik & \\
- Sistem Informasi Penerimaan Mahasiswa Baru & \\
\hline - Sistem Informasi Penggajian Karyawan & - Website STMIK WICIDA \\
- Sistem Informasi Pelayanan Pembayaran & \\
$\quad$ Mahasiswa & \\
\hline Key Operational & Support \\
\hline
\end{tabular}

D. Analisis Lingkungan Bisnis Internal

Analisis ini bertujuan untuk mengenali aspek-aspek strategis pada STMIK WICIDA sehingga diperoleh gambaran yang jelas dari kebutuhan institusi saat ini. Alat yang digunakan untuk melakukan analisis ini adalah Value Chain Analysis. Rantai aktivitas pada STMIK WICIDA dapat dilihat pada Gambar 4.

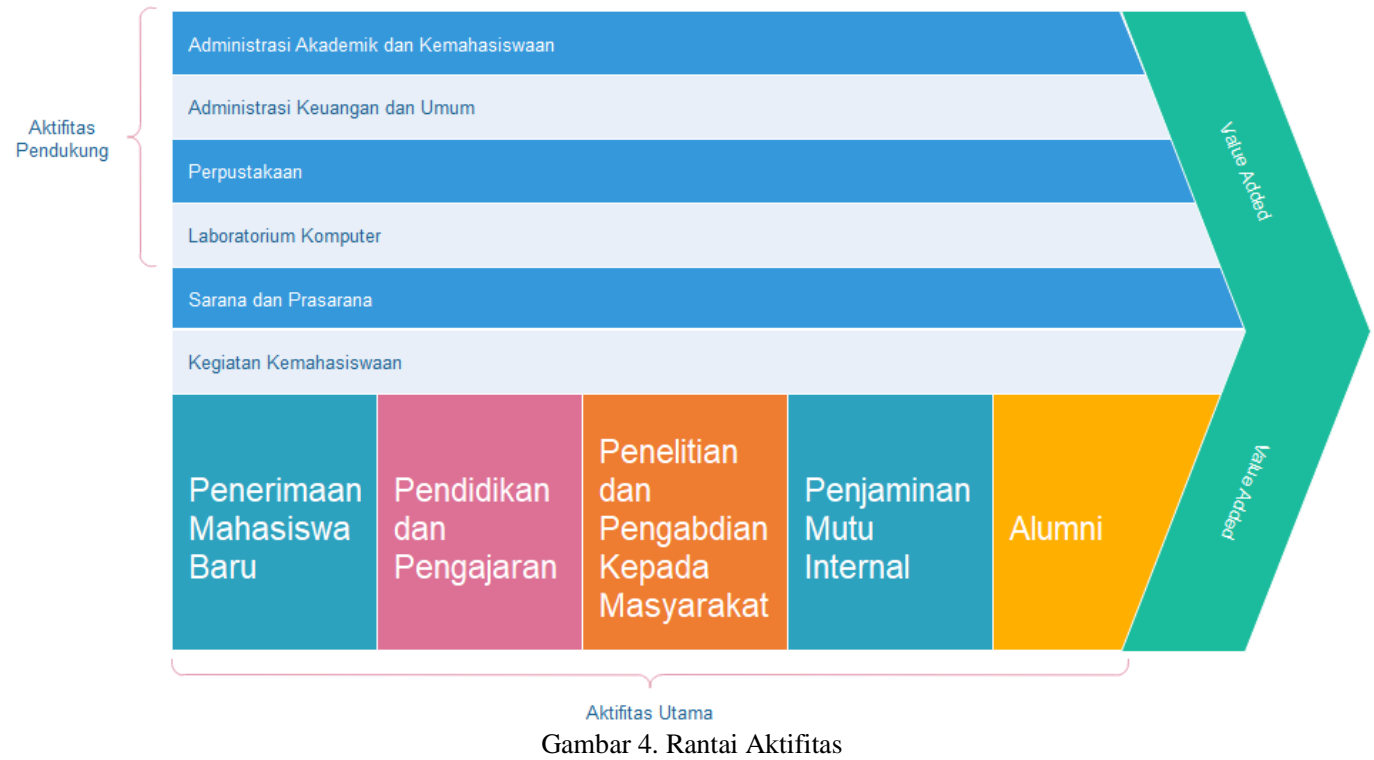


Hasil Value Chain Analysis dapat dilihat pada Tabel 4 .

TABEL 4

HASIL VALUE CHAIN ANALYSIS

\begin{tabular}{|c|c|}
\hline Aktifitas Utama & \\
\hline Rantai Aktifitas & Kebutuhan SI/TI \\
\hline Penerimaan Mahasiswa Baru & $\begin{array}{l}\text { Sistem Informasi Penerimaan Mahasiswa Baru } \\
\text { berbasis web yang memungkinkan calon } \\
\text { mahasiswa melakukan registrasi Online tanpa } \\
\text { harus datang ke kampus. Sistem informasi ini juga } \\
\text { dimanfaatkan sebagai saluran promosi kampus. }\end{array}$ \\
\hline Pendidikan dan Pengajaran & $\begin{array}{l}\text { Learning Management System yang dapat } \\
\text { mempermudah dosen untuk menyampaikan } \\
\text { materi ajar, melakukan proses belajar mengajar } \\
\text { dan melakukan evaluasi pembelajaran, } \\
\text { mempermudah mahasiswa dalam mendapatkan } \\
\text { materi ajar yang interaktif serta mempermudah } \\
\text { bagian administrasi akademik dalam pengelolaan } \\
\text { mahasiswa. }\end{array}$ \\
\hline Penelitian dan Pengabdian Kepada Masyarakat & $\begin{array}{l}\text { Sistem Informasi Penelitian dan Pengabdian } \\
\text { Kepada Masyarakat yang mempermudah dosen } \\
\text { dalam mengelola administrasi penelitian dan } \\
\text { pengabdian kepada masyarakat. Sistem informasi } \\
\text { ini terpadu dengan Open Journal System untuk } \\
\text { publikasi ilmiah dosen. }\end{array}$ \\
\hline Penjaminan Mutu Internal & $\begin{array}{l}\text { Sistem Informasi Penjaminan Mutu Internal yang } \\
\text { menampilkan ringkasan eksekutif sebagai bahan } \\
\text { pengambilan keputusan pimpinan, sebagai bahan } \\
\text { dalam melakukan evaluasi diri, dan menjadi } \\
\text { masukan untuk perbaikan proses bisnis secara } \\
\text { menyeluruh. }\end{array}$ \\
\hline Alumni & $\begin{array}{l}\text { Sistem Informasi Alumni yang mempunyai fitur } \\
\text { pelacakan alumni (tracer study), penempatan } \\
\text { kerja (job placement center), dan pemberdayaan } \\
\text { alumni, }\end{array}$ \\
\hline
\end{tabular}

\begin{tabular}{ll}
\hline \hline Aktifitas Pendukung & Kebutuhan SI/TI \\
\hline Rantai Aktifitas & Sistem Informasi Akademik yang mencakup \\
pdministrasi Akademik dan Kemahasiswaan & $\begin{array}{l}\text { administrasi akademik mahasiswa, } \\
\text { penjadwalan perkuliahan, penilaian. }\end{array}$ \\
\hline Administrasi Umum dan Keuangan & Sistem Informasi Kepegawaian yang mengelola \\
& data karyawan yang terdiri dari tenaga pendidik, \\
& tenaga kependidikan dan tenaga administrasi. \\
& Sistem Informasi Keuangan yang mencakup \\
& pengelolaan keuangan institusi dan penerimaan \\
pembayaran dari mahasiswa
\end{tabular}

E. Perencanaan Strategis Sistem Informasi

Perencanaan strategis sistem informasi pada STMIK WICIDA disusun berdasarkan hasil analisis lingkungan bisnis eksternal, analisis lingkungan bisnis internal, analisis lingkungan IS/IT eksternal dan analisis lingkungan IS/IT internal. Hasil analisis digunakan untuk menentukan strategi bisnis sistem informasi, strategi manajemen IS/IT dan strategi IT.

Dari hasil analisis PEST didapatkan kebutuhan IS/IT antara lain : Sistem Informasi Akademik, 
Learning Management System untuk Pembelajaran Jarak Jauh (PJJ), Website STMIK WICIDA, Job Placement Center, Sistem Informasi Beasiswa CSR, pengembangan aplikasi mobile.

Dari hasil analisis lingkungan IS/IT eksternal pada pengembangan sistem informasi perlu dipertimbangkan penggunaan teknologi terbaru dan memanfaatkan teknologi seperti aplikasi web, aplikasi mobile, cloud computing dan Open Source LMS yang dapat menjadi salah satu keunggulan kompetitif STMIK WICIDA.

Dari hasil value Chain analysis didapatkan kebutuhan IS/IT antara lain : Sistem Informasi Penerimaan Mahasiswa Baru, Learning Management System, Sistem Informasi Penelitian dan Pengabdian Kepada Masyarakat, Open Journal System, Sistem Penjaminan Mutu Internal, Sistem Informasi Alumni, Sistem Informasi Akademik, Sistem Informasi Kepegawaian, Sistem Informasi Keuangan, Sistem Informasi Perpustakaan, Digital Library, Sistem Informasi Laboratorium Komputer, Sistem Informasi Sarana dan Prasarana, dan Sistem Informasi Kemahasiswaan.

Portofolio aplikasi SI yang sesuai kebutuhan di masa mendatang dipetakan lagi menggunakan mcFarlan Strategic Grid dimana didapatkan hasil seperti pada Error! Reference source not found.

TABEL 5

RENCANA PORTOFOLIO APLIKAS

\begin{tabular}{ll}
\hline \hline Strategic & High Potential \\
\hline - Sistem Informasi Penerimaan Mahasiswa Baru & - LMS untuk PJJ \\
- Job Placement Center & - Sistem Informasi Beasiswa \\
- Open Journal System & CSR \\
- Sistem Informasi Kemahasiswaan & - Digital Library \\
- Sistem Informasi Alumni & - Website STMIK WICIDA \\
\hline - Sistem Informasi Akademik & - Sistem Informasi Sarana dan \\
- Sistem Informasi Kepegawaian & Prasarana \\
- Sistem Informasi Keuangan & \\
- Sistem Informasi Penelitian dan Pengabdian Kepada & \\
- Masyarakat. & \\
- Sistem Informasi Perpustakaan & Support \\
\hline Key Operational & \\
\hline
\end{tabular}

F. Rencana Implementasi Perencanaan Strategis Sistem Informasi

Dengan mengacu pada analisis mcFarlan Strategic Grid dapat ditentukan prioritas sistem informasi yang harus dikembangkan dengan urutan key operasional, support, strategic dan high potential. Prioritas sistem informasi dan jadwal implementasi perencanaan strategis sistem informasi yang akan dikembangkan dapat dilihat pada Tabel 6.

TABEL 6

RENCANA IMPLEMENTASI PERENCANAAN STRATEGIS SISTEM INFORMASI

\begin{tabular}{|c|c|c|c|c|c|c|c|c|}
\hline \multirow{2}{*}{ No. } & \multirow{2}{*}{ Sistem Informasi } & \multirow{2}{*}{ Status } & \multicolumn{2}{|c|}{ Tahun 1} & \multicolumn{2}{|c|}{ Tahun 2} & \multicolumn{2}{|c|}{ Tahun 3} \\
\hline & & & S1 & S2 & S1 & S2 & S1 & S2 \\
\hline 1. & Sistem Informasi Akademik & $\mathrm{P}$ & $\mathrm{x}$ & & & & & \\
\hline 2. & $\begin{array}{l}\text { Sistem Informasi Penelitian dan Pengabdian Kepada } \\
\text { Masyarakat }\end{array}$ & B & $\mathrm{x}$ & & & & & \\
\hline 3. & Sistem Informasi Laboratorium Komputer & $\mathrm{B}$ & $\mathrm{x}$ & & & & & \\
\hline 4. & Sistem Informasi Keuangan & $\mathrm{P}$ & & $\mathrm{x}$ & & & & \\
\hline 5. & Sistem Informasi Kepegawaian & $\mathrm{B}$ & & $\mathrm{x}$ & & & & \\
\hline 6. & Sistem Informasi Perpustakaan & $\mathrm{B}$ & & $\mathrm{x}$ & & & & \\
\hline 7. & Website & $\mathrm{P}$ & & & $\mathrm{x}$ & & & \\
\hline 8. & Sistem Informasi Sarana dan Prasarana & $\mathrm{B}$ & & & $\mathrm{x}$ & & & \\
\hline 9. & Sistem Informasi Alumni & $\mathrm{B}$ & & & $\mathrm{x}$ & & & \\
\hline 10. & Sistem Informasi Penerimaan Mahasiswa Baru & $\mathrm{P}$ & & & & $\mathrm{x}$ & & \\
\hline 11. & Open Journal System & $\mathrm{B}$ & & & & $\mathrm{x}$ & & \\
\hline 12. & Sistem Informasi Kemahasiswaan & $\mathrm{B}$ & & & & $\mathrm{X}$ & & \\
\hline 13. & Job Placement Center & $\mathrm{B}$ & & & & & $\mathrm{x}$ & \\
\hline 14. & LMS & $\mathrm{B}$ & & & & & $\mathrm{x}$ & \\
\hline 15. & Sistem Informasi Beasiswa CSR & $\mathrm{B}$ & & & & & $\mathrm{x}$ & \\
\hline 16. & Digital Library & B & & & & & & $\mathrm{X}$ \\
\hline
\end{tabular}

Catatan :

$\mathrm{B}=$ Baru

$\mathrm{P}=$ Pengembangan 


\section{KESIMPULAN}

Dari hasil analisis yang dilakukan pada perencanaan strategis sistem informasi pada STMIK WICIDA dapat ditarik kesimpulan sebagai berikut :

a. Hasil analisis PEST dan Value Chain Analysis menunjukkan STMIK WICIDA harus mengembangkan 4 sistem informasi yang sedang berjalan dan membuat 12 sistem informasi baru. Learning Management System, Sistem Informasi Beasiswa CSR dan Digital Library merupakan aplikasi yang mempunyai portofolio High Potential.

b. Rencana implementasi perencanaan strategis sistem informasi disesuaikan dengan rencana strategis STMIK WICIDA dan dibagi dalam 3 tahun pelaksanaan.

\section{SARAN}

Untuk pengembangan selanjutnya dari penelitian ini disarankan adalah menggunakan tools lain dalam melakukan analisis lingkungan eksternal dan internal dan analisis lingkungan IS/IT eksternal dan internal sebagaimana yang direkomendasikan Ward dan Pepperd.

\section{DAFTAR PUSTAKA}

[1] Heriadi, M. Suyanto dan Sudarmawan, "Perencanaan Strategis Sistem Informasi STMIK Cahaya Surya Kediri," Citec Journal, pp. 15 - 24, 2014.

[2] Susena, E. Utami dan A. Sunyoto, "Perencanaan Strategis Sistem Informasi Smart Campus untuk Meningkatkan Pelayanan di Politeknik Indonusa Surakarta,” Jurnal Sainstech Politeknik Indonusa Surakarta, pp. 1 - 17, 2015.

[3] L. Suryadi, "Perencanaan Strategis Sistem Informasi dan Teknologi Informasi (SI/TI) : Studi Kasus Universitas Budi Luhur," Telematika, 2011.

[4] S. P. C. M. Robbins, Manajemen, Jakarta: PT. Prenhallindo, 1999.

[5] P. J. Ward, Strategic Planning for Information System, England: John Willey \& Sons, 2002.

[6] O’Brien, Introduction to Information Systems, New York: McGraw Hill, 2003. 